\title{
Fast-response high-resolution temperature sonde aimed at contamination-free profile observations
}

\author{
K. Shimizu ${ }^{1,2}$ and F. Hasebe ${ }^{3}$ \\ ${ }^{1}$ Graduate School of Environmental Science, Hokkaido University, Kita 10 Nishi 5, Kita-ku, Sapporo, 060-0810, Japan \\ ${ }^{2}$ Meisei Electric Co., Ltd., 2223 Naganuma-cho, Isesaki, 372-8585, Japan \\ ${ }^{3}$ Faculty of Environmental Earth Science, Hokkaido University, Kita 10 Nishi 5, Kita-ku, Sapporo, 060-0810, Japan
}

Received: 8 July 2010 - Published in Atmos. Meas. Tech. Discuss.: 6 August 2010

Revised: 29 November 2010 - Accepted: 1 December 2010 - Published: 6 December 2010

\begin{abstract}
An innovative temperature sonde, equipped with an ultra thin tungsten wire ( $10 \mu \mathrm{m}$ in diameter), has been developed to meet the scientific requirements suitable for climate change research. The response time, shorter than $40 \mathrm{~ms}$ achieved at the altitude of $30 \mathrm{~km}$, enables the temperature observations with the radiation correction of less than $0.5 \mathrm{~K}$ in the whole observation range. Test flights during the development stage reveal significant artificial perturbations in the observed temperature profiles. They are identified as the thermal contamination arising primarily from radiosonde package box with some additional effect from the launching balloon. The modification of the sensor mount successfully removed the contribution from the former effect. On the other hand, some filtering procedure need to be applied to remove the latter, although the use of a long suspension line will be effective. There remain unavoidable small fluctuations (less than $0.4 \mathrm{~K}$ ) that are brought about by the solid angle modulation of the illumination against the sensor body in the daytime. While conventional radiation correction may unintentionally have taken a part of such contaminations into account, they may not be properly corrected in existing radiosonde data, as the origin of errors has not been identified. Our tungsten sonde that scarcely relies on the ambiguous correction procedures will be ideal for serving as a kind of an international reference.
\end{abstract}

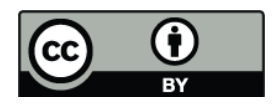

Correspondence to: K. Shimizu (shimizuk@ees.hokudai.ac.jp)

\section{Introduction}

Important roles of the stratosphere on climate have emerged from recent studies. The changes in the strength of the winter-time stratospheric polar vortex are accompanied by the persistent changes in the tropospheric flow (Baldwin and Dunkerton, 2001) through the Northern Annular Mode (Thompson and Wallace, 2000). The Southern Annular Mode could bridge the stratospheric cooling due to the Antarctic ozone depletion (Solomon, 1990) to the surface cooling trend over Antarctica (Thompson and Solomon, 2002). The change of stratospheric water possibly affect the long-term surface warming trend (Solomon et al., 2010). As the entry of water through the tropical tropopause is delicately determined by the coldness (Brewer, 1949; Newell and Gould-Stewart, 1981; Holton and Gettelman, 2001) and the heat balance including thin cirrus clouds (Hartmann et al., 2001; Yang et al., 2010), accurate measurements of temperature, wind and radiatively active minor constituents such as ozone and water vapour are crucial for monitoring the stratospheric change. A qualified continuous and homogeneous observation network of the upper atmosphere must be established for monitoring the climate change (Seidel et al., 2009). Accurate stratospheric measurements, together with the sophisticated data assimilation technique, will also serve to improve the extended weather forecasts.

Balloon-borne radiosondes are the only cost-efficient means that simultaneously measure vertical profiles of temperature, humidity and wind components of the upper atmosphere. In spite of the recent progress in the observation tools such as the Global Positioning System (GPS) in temperature measurements (Nishida et al., 2000) and satellite-derived atmospheric motion vectors (e.g., Bedka and Mecikalski,

Published by Copernicus Publications on behalf of the European Geosciences Union. 
2005), radiosondes still provide crucial reference data for weather forecasts and validation of remote sensing instruments (Mears and Wentz, 2005). One of the problems recognized for the global radiosonde network is that there found frequent and often undocumented changes in instrumentation and observing methods (Gaffen, 1994). The correction of the solar heating on the sensor is of the greatest concern since it creates a spurious long-term trend in radiosonde temperature record (Sherwood et al., 2005). The assessment of climate change has, therefore, devoted considerable effort to improve the quality of historical radiosonde data (Luers and Eskridge, 1998; Karl et al., 2006; Solomon et al., 2007). The development of a reliable temperature sensor that is almost free from radiation correction is highly anticipated (Immler et al., 2010).

It is still a challenge to create a reliable temperature sensor for radiosondes that should cover wide dynamic ranges of temperature $\left(50\right.$ to $\left.-90^{\circ} \mathrm{C}\right)$ and pressure $(1000$ to $5 \mathrm{hPa}$ ) under insolation. Actually there remain significant differences between temperatures simultaneously measured by radiosondes from different manufacturers due probably to inaccurate radiation correction (Nash et al., 2006). In the present study, a new temperature sonde intended to serve as an international reference is developed (Sect. 2). The profiles observed during the initial development stage are found to be full of heat pulses, which suggests that such perturbations, part of which may have already shown up in the current radiosonde data, have not been dealt with seriously since they are not fully resolved in the observed record (Sect. 3). Sources of such contamination are identified by series of test flights. Highresolution contamination-free temperature profiles are finally obtained by changing the design of the sensor mount. The conclusions together with some remarks are placed in Sect. 4.

\section{Development of tungsten radiosonde}

The deviation of the observed temperature, $T_{\mathrm{s}}$, from the atmospheric temperature, $T_{\mathrm{a}}$, will be expressed by

$$
T_{\mathrm{s}}-T_{\mathrm{a}}=\frac{1}{H}\left\{\alpha \times \frac{S}{A}+\epsilon\left(\frac{L}{A}-\sigma T_{\mathrm{s}}^{4}\right)+\frac{I^{2} R}{A}\right\}+T_{\mathrm{b}},
$$

where $H$, the heat transfer coefficient, is inversely proportional to the response time $\tau$ in the form

$H=\frac{m C}{\tau A}$.

Here, $A, R, m$ and $C$ are the surface area, electric resistance, mass and specific heat, respectively, and $\alpha$ and $\epsilon$ are the short- and long-wave emissivity, respectively, of the sensor, $S$ and $L$ are the total incoming short- and long-wave flux, respectively, across the surface of the sensor, $\sigma$ is the StefanBoltzmann constant (McMillin et al., 1992), $I$ is the electric current applied to the sensor, and $T_{\mathrm{b}}$ is the mean bias. $H$ is

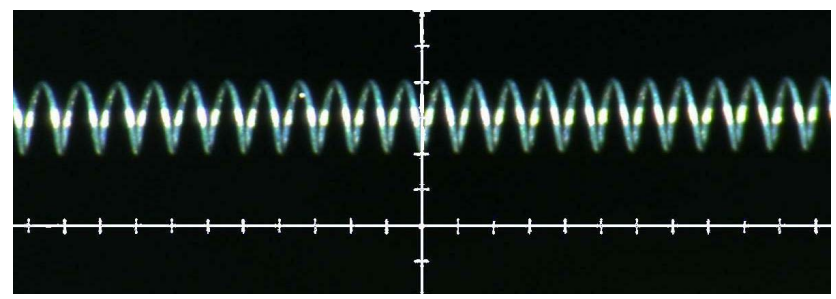

Fig. 1. Microscope photograph of the temperature sensor made of a tungsten wire of $10 \mu \mathrm{m}$ in diameter wound up in a helical coil with the diameter of $200 \mu \mathrm{m}$ and the pitch of $100 \mu \mathrm{m}$. Tick marks on the scale in every $100 \mu \mathrm{m}$.

expressed by the sum of two terms; the diffusion heat transfer coefficient $H_{\mathrm{d}}$ associated with the molecular diffusion and the convection heat transfer coefficient $H_{\mathrm{c}}$ due to the atmospheric motion. $H_{\mathrm{c}}$ is further expressed by a function of the Reynolds number $f(R e)$ in the form

$H_{\mathrm{c}}=\frac{k}{d} \times f(R e)$.

Here, $k$ is the thermal conductivity and $d$ is the diameter of the sensor wire. $R e$ is defined by $\rho a w / \mu$, where $a$ is the characteristic length of the sensor assumed to be the same as $d, w$ is the wind speed, and $\rho$ and $\mu$ are the density and the coefficient of viscosity, respectively, of the atmosphere. Accurate sensors could be designed, therefore, by choosing materials with large values of $H$ and reducing the total radiative flux and Joule heating applied to the sensor as well as reducing $T_{\mathrm{b}}$.

The new sensor we have developed relies on the temperature dependency of the electric resistance of a tungsten wire applied once for rocket sondes (Hyson, 1968). The wire, aluminum coated to improve reflectivity (Fig. 1), is so thin $(10 \mu \mathrm{m}$ in diameter with the total length of $44 \mathrm{~cm})$ that the relaxation time, almost constant with respect to the atmospheric pressure as can be seen from the green symbols in Fig. 2, is $46 \mathrm{~ms}$ under $300 \mathrm{~K}$ and $1 \mathrm{~atm}(1013.25 \mathrm{hPa})$ at rest. Substitution of this value, together with physical parameters, into Eq. (2) would lead to the diffusion heat transfer coefficient $H_{\mathrm{d}}=1.36 \times 10^{2} \mathrm{~W} \mathrm{~K}^{-1} \mathrm{~m}^{-2}$ since $H_{\mathrm{c}}=0$ at rest.

Numerical values of the heat transfer coefficient $H=$ $H_{\mathrm{d}}+H_{\mathrm{c}}$ are experimentally derived by applying the wind flow of up to $5.5 \mathrm{~m} \mathrm{~s}^{-1}$ with an increment by $0.5 \mathrm{~m} \mathrm{~s}^{-1}$ to the sensor (the red symbols in Fig. 2). Assuming the temperature dependency in the form $k=0.024$ $(T / 273.15)^{0.913} \mathrm{~W} \mathrm{~K}^{-1} \mathrm{~m}^{-1}$, which is derived from the numerical data tabulated by National Physical Laboratory (Kaye and Laby, 2008), $H$ for the tungsten sensor has reduced to the form

$H=\frac{k}{d}\left(0.052+0.168 R e^{0.564}\right)$.

The response time will be about $40 \mathrm{~ms}$ at $10 \mathrm{hPa}$ (near $30 \mathrm{~km}$ ) level (Table 1) under the typical ascending rate of $5 \mathrm{~m} \mathrm{~s}^{-1}$. 
Table 1. Typical values of the time constant (relaxation time; $\tau \mathrm{ms}$ ) of the sensor, systematic errors (K) arising from solar short-wave (SW) and terrestrial long-wave (LW) radiations, and measurement-current induced Joule heating for the virtual sounding in a midlatitude model atmosphere specified in the upper rows. $\mathrm{D}$ and $\mathrm{U}$ stand for the radiation $\left(\mathrm{W} \mathrm{m}^{-2}\right)$ in downward and upward, respectively. $5 \mathrm{~m} \mathrm{~s}^{-1}$ is assumed for the ascending velocity of radiosonde. Those values in the second row in SW and Joule are the specifications after an upgrade of May 2010.

\begin{tabular}{|c|c|c|c|c|c|c|c|c|}
\hline Altitude & $\mathrm{km}$ & 0 & 5 & 10 & 15 & 20 & 25 & 30 \\
\hline \multicolumn{9}{|c|}{ Model atmosphere } \\
\hline Pressure & $\mathrm{hPa}$ & 1013.3 & 540.5 & 264.5 & 121.1 & 55.3 & 25.5 & 12.0 \\
\hline Temperature & ${ }^{\circ} \mathrm{C}$ & 15.0 & -17.5 & -49.9 & -56.5 & -56.5 & -51.6 & -46.6 \\
\hline $\operatorname{Re}$ & & 3.39 & 2.24 & 1.40 & 0.676 & 0.309 & 0.137 & 0.0618 \\
\hline SW/D & $\mathrm{W} \mathrm{m}^{-2}$ & 1350 & 1350 & 1350 & 1350 & 1350 & 1350 & 1350 \\
\hline SW/U & $\mathrm{W} \mathrm{m}^{-2}$ & 405 & 405 & 405 & 405 & 405 & 405 & 405 \\
\hline LW/D & $\mathrm{W} \mathrm{m}^{-2}$ & 166 & 49 & 23 & 21 & 22 & 21 & 34 \\
\hline $\mathrm{LW} / \mathrm{U}$ & $\mathrm{W} \mathrm{m}^{-2}$ & 318 & 275 & 272 & 259 & 241 & 230 & 222 \\
\hline \multicolumn{9}{|c|}{ Response time and systematic errors } \\
\hline$\tau$ & $\mathrm{ms}$ & 6.4 & 8.8 & 12.6 & 18.1 & 24.9 & 32.4 & 39.9 \\
\hline \multirow{2}{*}{ SW } & \multirow{2}{*}{ K } & 0.122 & 0.167 & 0.237 & 0.336 & 0.460 & 0.595 & 0.726 \\
\hline & & 0.072 & 0.099 & 0.140 & 0.199 & 0.272 & 0.351 & 0.429 \\
\hline LW & $\mathrm{K}$ & -0.005 & -0.003 & 0.000 & 0.001 & 0.001 & -0.002 & -0.004 \\
\hline \multirow{2}{*}{ Joule } & \multirow{2}{*}{$\mathrm{K}$} & 0.026 & 0.036 & 0.051 & 0.072 & 0.099 & 0.128 & 0.156 \\
\hline & & 0.007 & 0.009 & 0.013 & 0.018 & 0.025 & 0.032 & 0.039 \\
\hline
\end{tabular}

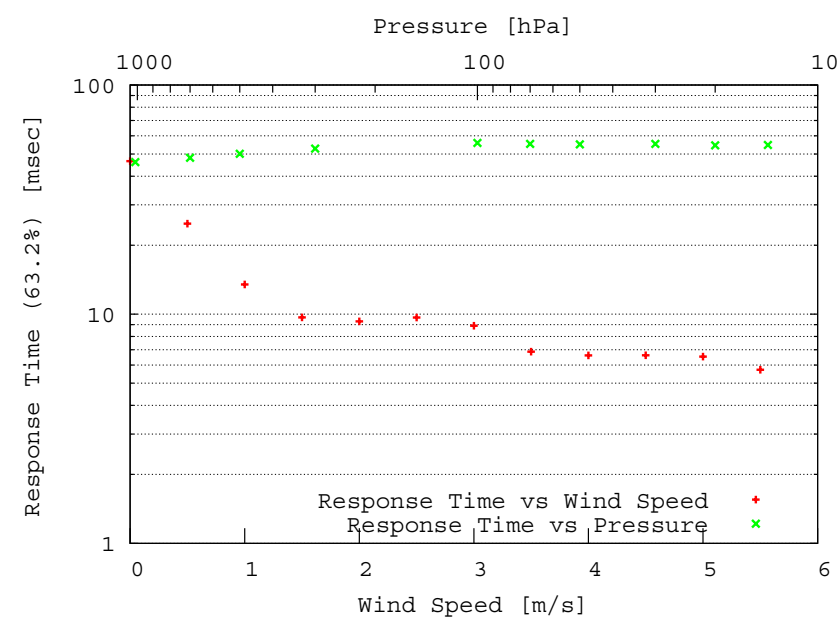

Fig. 2. Laboratory measurements of the response time $\tau$ of the tungsten sensor. Those shown in green describe the variabilities of $\tau$ as a function of atmospheric pressure at rest (upper scale), while those in red illustrate the decrease in $\tau$ with respect to wind speed at $300 \mathrm{~K}$ and $1 \mathrm{~atm}$ (lower scale).

This is at least one order of magnitude faster than operationally used temperature sensors (World Meteorological Organization, 2008).

The sensor bias $T_{\mathrm{b}}$ is estimated from the following laboratory experiments. The electric resistance of the tungsten sensor is converted to the frequency of an alternative current, which is counted to digital values by a signal conditioner. The errors ( 1 standard deviation) associated with the frequency conversion are less than $0.05 \mathrm{~K}$, while those in the signal conditioner correspond to $0.04 \mathrm{~K}$. Our signal conditioner has a repeatability of $0.02 \mathrm{~K} . T_{\mathrm{b}}$ is thus expected to be less than $0.07 \mathrm{~K}$ if we assume the errors listed above are mutually independent and that the law of propagation of errors (e.g., Abernethy and Benedict, 1985) is applicable. $T_{\mathrm{b}}$ is also subject to systematic drift associated with the temperature change of the thermally protected circuit board in the radiosonde. The estimated drift is $0.07 \mathrm{~K}$ in the operational range from $-30^{\circ} \mathrm{C}$ to $+50{ }^{\circ} \mathrm{C}$. All these considered, the maximum value of $T_{\mathrm{b}}$ estimated in the laboratory will not exceed $0.14 \mathrm{~K}$. Since there is no traceable standard for measuring temperature in the UTLS, however, the absolute accuracy in filed observations is not rigorously quantifiable.

The advantages of using fast-responding sensors are not restricted to the possible detectability of the atmospheric fine structure; we could minimize inaccurate radiation correction as well since $T_{\mathrm{s}}-T_{\mathrm{a}}$ is proportional to the response time $\tau$ as can be seen from Eqs. (1) and (2). The new tungsten sensor has a daytime radiation correction as small as $0.7 \mathrm{~K}(0.5 \mathrm{~K}$ after an upgrade by improving the surface reflectivity and reducing the applied current in May 2010) at the altitude of $30 \mathrm{~km}$. Those specifications are experimentally confirmed in a chamber equipped with the solar simulator. The overall values remain essentially unchanged in the real atmosphere, although they are subject to change depending on the solar zenith angle and the scattering from clouds. The tungsten 
sensor thus developed is mounted on a radiosonde enabling the data transmission at a rate of $6 \mathrm{~Hz}$ after the output is lowpass-filtered at $3 \mathrm{~Hz}$. The resultant vertical resolution is $2 \mathrm{~m}$ for the typical soundings.

\section{Observed temperature profiles}

A series of field observations are conducted at Moriya, Japan $\left(35.93^{\circ} \mathrm{N}, 140.00^{\circ} \mathrm{E}\right)$ and Biak, Indonesia $\left(1.17^{\circ} \mathrm{S}\right.$, $136.06^{\circ} \mathrm{E}$ ) trying to examine the performance of the tungsten sonde by simultaneously launching conventional radiosondes. Two examples, one during the day and the other during the night, are shown in Fig. 3. Good agreement between the profiles from the tungsten sonde (red) and the conventionally used Meisei RS06G (blue) and Vaisala RS80 (green) radiosondes is confirmed in the troposphere below $5 \mathrm{~km}$ during the day (left) and below $15 \mathrm{~km}$ during the night (right). However, there appear a number of spikes in those from the tungsten sondes in the directions positive during the day and negative at night superposed on the relatively smooth curves observed by conventional radiosondes. The magnitude of the spikes is generally larger during the day and grows with respect to altitude reaching as large as several Kelvins in the middle stratosphere around $30 \mathrm{~km}$.

Those smooth profiles from the conventional radiosondes are not the raw data but are the processed product. They are suitable for operational use on the one hand but insufficient for research purpose on the other as the details of processing are not well-documented. Actually, similar heat pulses, with the amplitude much smaller than that by tungsten sondes, have been detected by conventional radiosondes that have relatively short response time (Nash et al., 2006). They have been removed by numerical filters for operational purpose based on the interpretation that they are somehow caused by the balloon wake (World Meteorological Organization, 2008) even though there is no direct observational evidence. In the case of daytime RS06G observations, the filter has been designed to trace the lower temperature envelope.

In the present study, the sources of such perturbations are identified as the heat flow from the sonde package and the overhead balloon by taking the advantages of fast-response high-resolution tungsten sondes together with the aid of GPS.

\subsection{Sources of contamination}

The possibility that the balloon could produce perturbations in observed temperature may be pointed out first by comparisons of the temperature profiles taken during the ascent against those during the successive descent (Tiefenau and Gebbeken, 1989). During the night, the balloon, expanding with its internal pressure in quasi-equilibrium with the environment, is subject to adiabatic cooling that makes it much colder than the surrounding atmosphere especially in the stratosphere where temperature increases with respect to

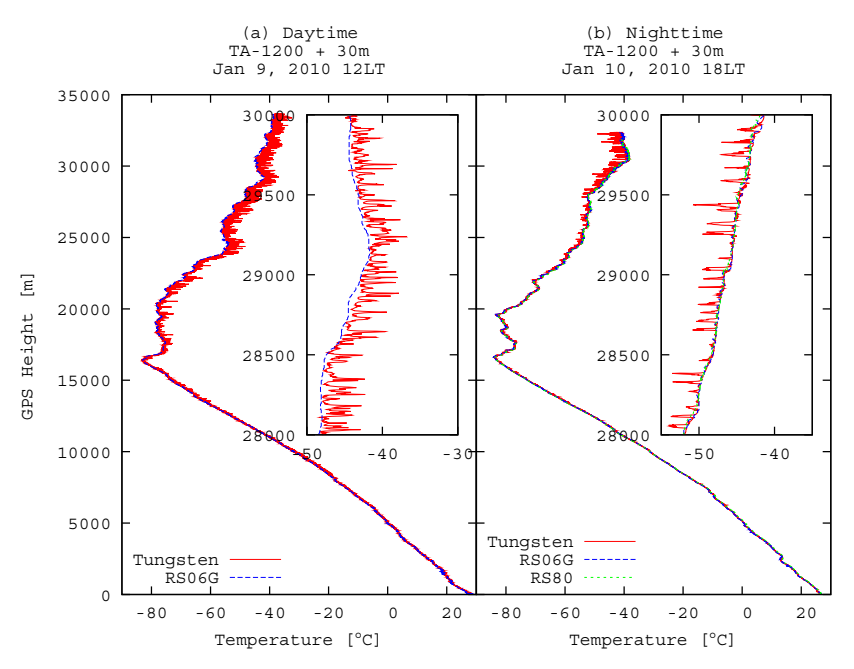

Fig. 3. Examples of the daytime (left) and nighttime (right) temperature $\left({ }^{\circ} \mathrm{C}\right)$ profiles at Biak, Indonesia $\left(1.17^{\circ} \mathrm{S}, 136.06^{\circ} \mathrm{E}\right)$ observed simultaneously by tungsten sonde (red), Meisei RS06G (blue) and Vaisala RS80 (green) radiosondes on 9 (left) and 10 (right) January 2010. For visual clarity, those from RS06G and RS80 sondes are drawn in dashed and dotted lines, respectively. Inset shows the details of the pulses in fine scale. 1200-gr balloon and 30-m suspension line are used for both flights.

altitude. On the other hand, solar heating exceeds adiabatic cooling during the day, which makes the balloon warmer than the environment. These effects will bring about the warm (cold) bias of the ascending profiles during the day (night). Another mechanism the balloon could induce errors in radiosonde temperature measurements is the possible deficit in the ventilation velocity when the sensor encounters the balloon wake (Luers and Eskridge, 1998). They argued that the reduced ventilation for the temperature sensor makes the cooling against solar heating less efficient, which leads to the positive bias in the daytime temperature measurements.

Possible influence from the balloon's air stream on the temperature sensor is analyzed by identifying its position relative to the balloon wake by 4-D GPS coordinates of both the balloon neck and the tungsten sonde. Figure 4 (left) shows the detailed structure of the temperature profiles observed by tungsten sondes. Owing to the sampling frequency of $6 \mathrm{~Hz}$, the fine structure of each heat pulse is clearly resolved in the profile. The right hand panel of Fig. 4 illustrates the projection of the ascending trajectories of the balloon (red) and the tungsten sonde (color-coded by temperature) on a meridional plane that is approximately parallel to the pendulum motion on that occasion. The abscissa indicates the horizontal distance of the balloon and the sonde, interpolated to constitute $6 \mathrm{~Hz}$ data from $1 \mathrm{~Hz}$ GPS coordinates, relative to the position of the sonde on its passage at the height of $31500 \mathrm{~m}$. Note that the short term change in the horizontal position could be accurately traced by successive GPS signal, although the overall uncertainty is approximately several 


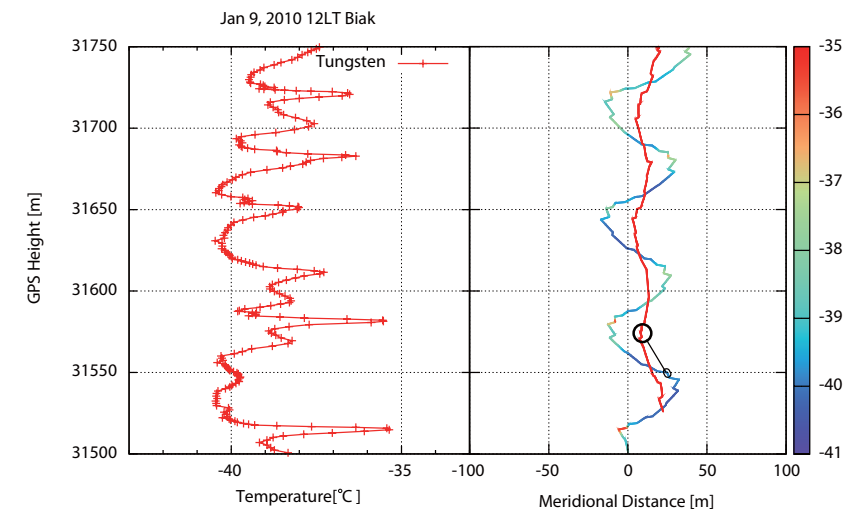

Fig. 4. Detailed temperature profiles from tungsten sonde (left) and the meridional projection of the trajectories for balloon (red) and sonde (color-coded by the temperature) estimated by GPS (right) taken from the daytime sounding at Biak, Indonesia on 9 January 2010. The illustration on the right hand panel is the symbolic view of the flight configuration; the circle with the diameter of about $10 \mathrm{~m}$ at the altitude of $31575 \mathrm{~m}$ is the balloon, while the small circle at $31550 \mathrm{~m}$ is the radiosonde swinging under the balloon. Large heat pulses correspond to the sonde's turn associated with the swing motion along the ascent. The sensor output has been low-pass filtered with the cut off at $3 \mathrm{~Hz}$ before the data transmission to the ground station at $6 \mathrm{~Hz}$. The resultant vertical resolution is about $2 \mathrm{~m}$. 1200-gr balloon and 30-m suspension line are used.

to $10 \mathrm{~m}$ depending on several conditions such as the number of available positioning satellites (e.g., Misra and Enge, 2001). On the other hand, as the GPS altitudes are not accurate enough to measure differential height, the vertical position of the balloon is assumed to be $25 \mathrm{~m}$ above the sonde referring to the length of the suspension line. What we can see from here is that the major heat pulses are not aligned in a cylindrical path along which the balloon has swept prior to the sonde; rather they are found mostly near the turning point of the swing. As the balloon's diameter at these altitudes is about $10 \mathrm{~m}$, those pulses are apparently out of the reach from the balloon wake while the balloon at that moment is rising almost straight in the atmosphere.

\subsection{Influence from radiosonde package box}

Possible source of contamination, apart from the balloon wake, is the influence from the radiosonde package box. As the sonde ascent is accompanied by swing motions (Fig. 4), air parcels thermally perturbed by the sonde package box may reach temperature sensor mounted on an arm sticking out from the sonde box. If this is the case, the contamination will depend on the alignment of the sticking arm and the swing motion. Such a possibility is examined by launching a pair of tungsten sondes each of which is fixed on the opposite end of a plate with the sensor arms directed to the outer side (Fig. 5). Under this configuration, the spin motion of individual sonde will disappear and one can expect that the

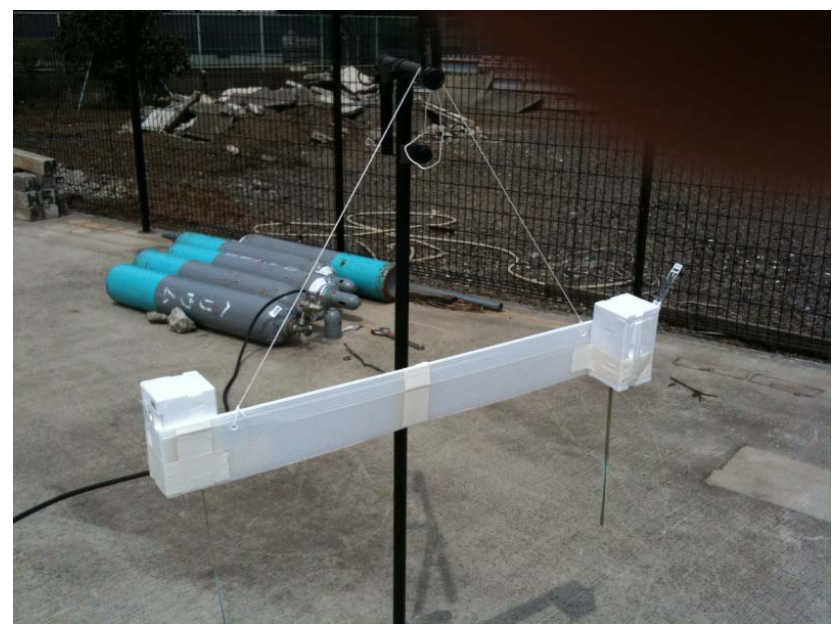

Fig. 5. Configuration of the dual launch of tungsten sondes for examining the radiosonde package box contamination.

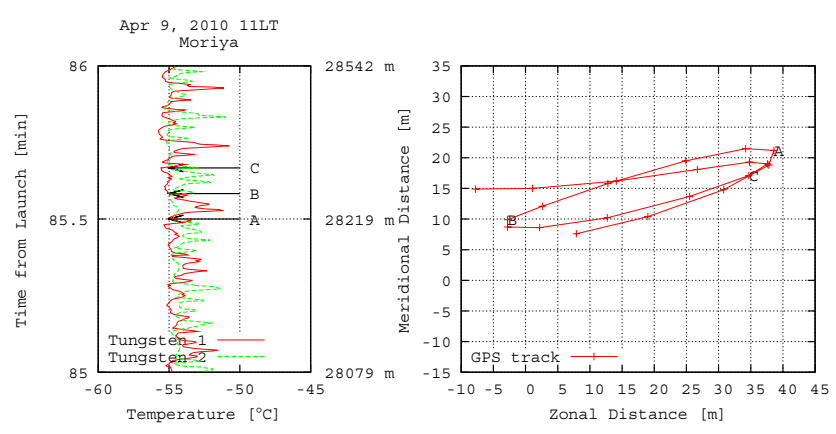

Fig. 6. Left: Temperature variations simultaneously measured by a paired tungsten sondes attached to a plate with the sensor arms directed to the opposite side (see Fig. 5). The ordinate is the time (min) after launch around 11:00 a.m. on 9 April 2010 at Moriya, Japan $\left(35.93^{\circ} \mathrm{N}, 140.00^{\circ} \mathrm{E}\right)$, covering the altitude range from 28.1 to $28.5 \mathrm{~km}$. Right: Horizontal projection of the sonde trajectories covering the altitude range specified by A, B and C in the left panel. 1200-gr balloon with the suspension line of $30 \mathrm{~m}$ is used.

swing motion is aerodynamically constrained in a manner in which one of the two sondes alternately follows the other (switchback motion) due to the plate. The observed temperature records are shown in the left panel of Fig. 6. Groups of pulses appear alternately in the two records with the time interval of about $12 \mathrm{~s}$, which roughly corresponds to the period of the pendulum motion. The horizontal projection of the sonde trajectories are shown in the right panel of Fig. 6. We can see the alternate appearances of the temperature pulses in the left panel are synchronized with the swing direction seen in the right panel. Although the differential position of the two sondes cannot be resolved by current GPS system, we can interpret that those temperatures observed by the follower are contaminated by the sonde box swinging ahead, 


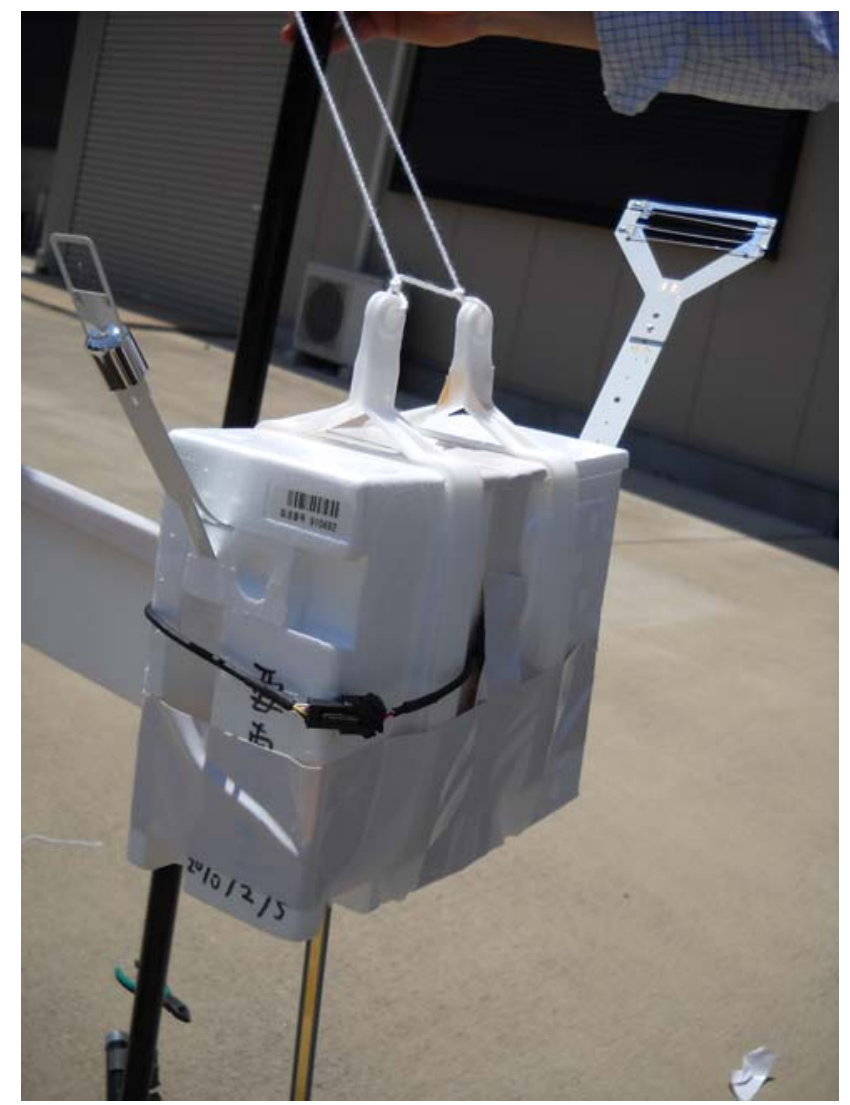

Fig. 7. Tungsten radiosonde with the modified sensor mount (far right) as compared to the conventional Meisei RS06G radiosonde (near left).

while those on the front are free from perturbations. These evidences support the idea that the temperature perturbations are due to the thermal interference from the radiosonde package box. These lessons led us to the configuration change of the original tungsten sonde by mounting the sensor perpendicular to the elongated arm so that the air flow thermally perturbed by sonde box will not reach it (Fig. 7).

\subsection{Influence from launching balloon}

The above modification successfully removed the perturbations originated from the sonde box. However, there still remain small pulses positive (negative) during the day (night) with the magnitude of about $0.5 \mathrm{~K}$ as can be seen from Fig. 8 . Since the magnitude of radiation correction for our tungsten sonde is about $0.7 \mathrm{~K}(0.5 \mathrm{~K}$ after upgrade $)$ at the altitude of $30 \mathrm{~km}$, the ventilation deficit (Luers and Eskridge, 1998) would not be the major process that has created above perturbations. Instead they are interpreted as the thermal influence from the launching balloon transported along the wake.

Balloon's in-flight skin temperature has been directly measured by placing thermistors in the balloon, one during the day and the other in the night. In each flight, three

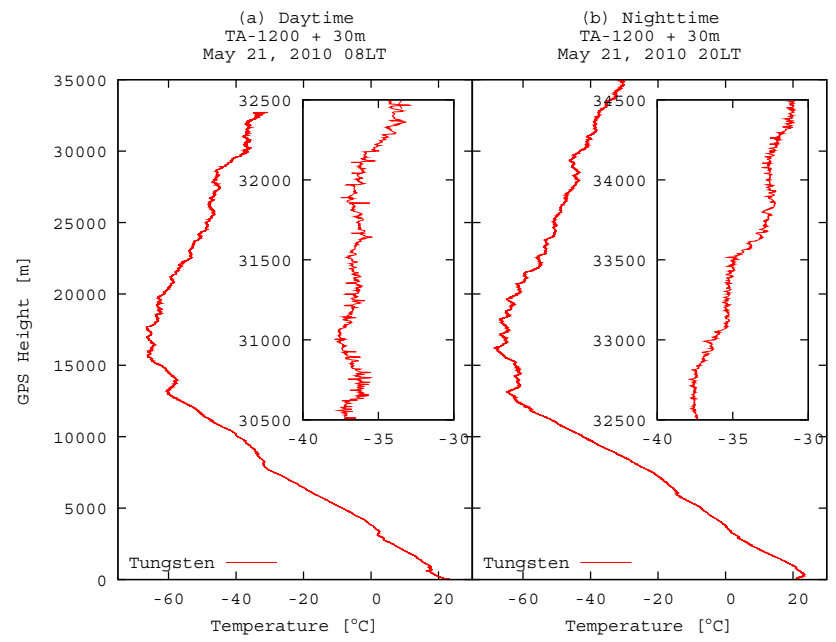

Fig. 8. The same as Fig. 3 but for those taken by the tungsten sondes after configuration change (see text for details). Observations are made at Moriya on 21 May 2010. The swing angle of the radiosonde with the suspension line of $30 \mathrm{~m}$ in this case reaches $40^{\circ}$, which is larger than the solar zenith angle of about $25^{\circ}$ for the daytime flight in (a).

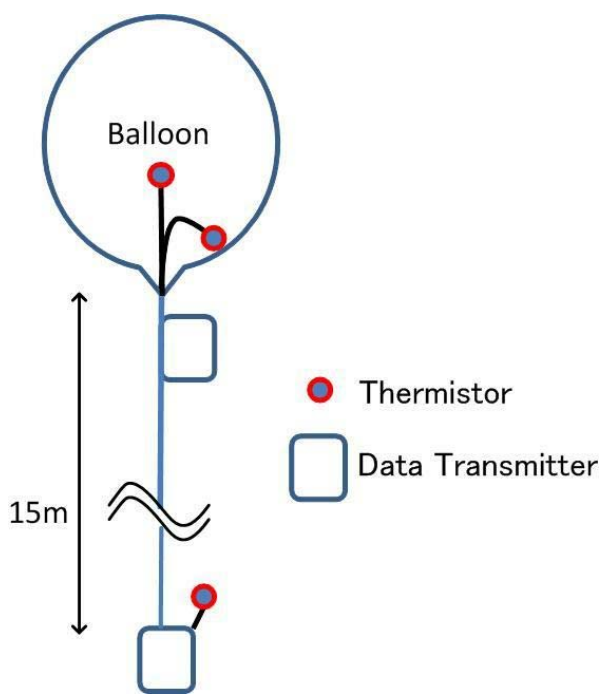

Fig. 9. The configuration of balloon's in-flight skin temperature observation. Three independent thermistors are installed to measure the temperatures both the inside and the outside ( $15 \mathrm{~m}$ below) the balloon in addition to the skin. The data of two thermistors in the balloon have been taken out to the outside through the valve.

independent thermistors are used to measure the temperatures both the inside and the outside ( $15 \mathrm{~m}$ below) the balloon in addition to the skin (Fig. 9). During the night with the tropopause crossing at around 9 PM (GMT + 9) (right-hand panel of Fig. 10), the observed inside temperature (blue) is generally lower than the outside (red) and the difference (purple) reaches about $15 \mathrm{~K}$ just before the balloon burst 


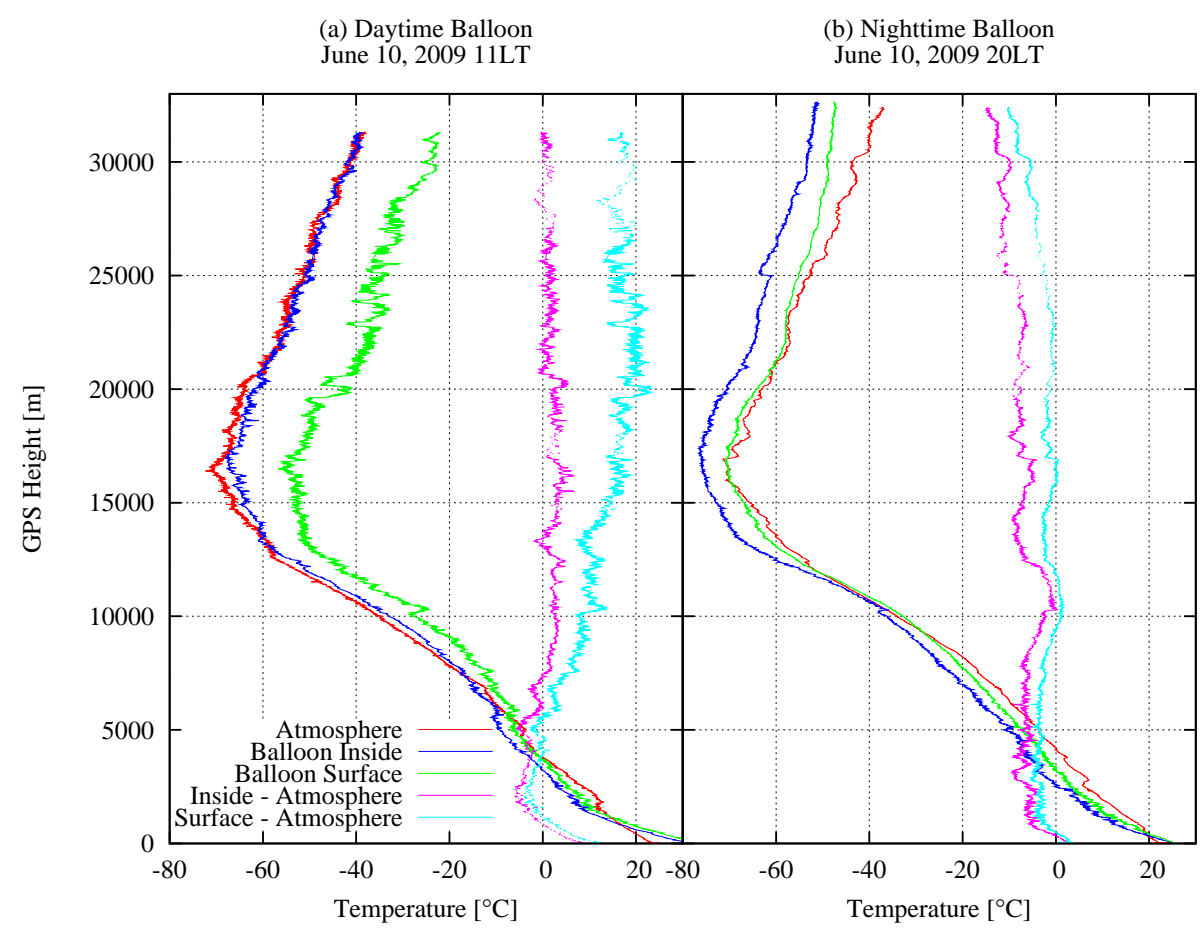

Fig. 10. Vertical profiles of the balloon's inside (green), outside (red) and the surface (blue) temperature $\left({ }^{\circ} \mathrm{C}\right.$ ) obtained by thermistors during the daytime (left) and nighttime (right) soundings at Moriya, Japan on 10 June 2009. Those in purple and light blue are the temperatures of balloon's inside and surface, respectively, relative to the outside. 1200-gr balloon was used for both flights.

near $32 \mathrm{~km}$. Balloon's skin temperature (green) is slightly lower than the outside, showing partly smoothed profile as compared to the outside variabilities. The systematic departure from the outside air temperature (light blue) starts from $23 \mathrm{~km}$ and grows up to reach $10 \mathrm{~K}$ at the ceiling level. In case of the daytime observations around noon (left-hand panel of Fig. 10), adiabatic cooling prevails the solar heating in the lower troposphere so that both the internal (blue) and the skin (green) temperatures are kept below the outside temperature (red) except for a couple of kilometers just after the launch, during which inside the balloon is warmer than the environment due to the warm inflation gas. However, the temperature difference reverses above the upper troposphere. Although the internal temperature stays within $10 \mathrm{~K}$ from the outside (purple), the skin temperature is found to exceed by $20 \mathrm{~K}$ as compared to the environment (light blue) in the stratosphere. The temperature of the balloon's top must have been much higher than those shown in this figure, as the thermistor sits in the less illuminated lower part of the balloon. Such a large perturbation in the balloon's skin temperature would be enough to create appreciable heat flow.

What were beyond our expectations is an intermittent negative pulses revealed in the daytime profile shown in Fig. 8. These are probably caused by the solar eclipse due to the overhead balloon, since they do not show up in the flights in which the solar zenith angle is larger than the swing angle of sonde's pendulum motion. Note that the shut off of solar radiation on the sensor will lead to the temperature reduction by $0.4 \mathrm{~K}$ with the response time of $40 \mathrm{~ms}$ at this altitude (Table 1). The contaminations originated from the heat flow and the shade effect due to the overhead balloon could be removed by some filtering procedure, because they appear specifically as steep pulses (Fig. 8). Alternatively, the influence from the balloon could be greatly reduced by using longer suspension line such as $120 \mathrm{~m}$ (Fig. 11). In this case, the heat flow along the balloon wake is almost negligible and the solar eclipse due to the balloon is hardly observed. Even under such conditions, however, there remain small perturbations with the magnitude of $\leq 0.4 \mathrm{~K}$ due probably to the variation of insolation associated with the solid angle change of the solar illumination against the sensor body. Accurate and contamination-free temperature profiles will be obtained from the nighttime soundings of the tungsten sonde made with long suspension lines. Our fast-response highresolution tungsten sondes might be applicable to collect descending data that are free from balloon wake.

\section{Concluding remarks}

A novel temperature sensor made of an ultra thin tungsten wire has been developed. It is mounted on a radiosonde enabling the data transmission at a rate of $6 \mathrm{~Hz}$. Due to the short response time of about $40 \mathrm{~ms}$ at around $30 \mathrm{~km}$, the radiation 


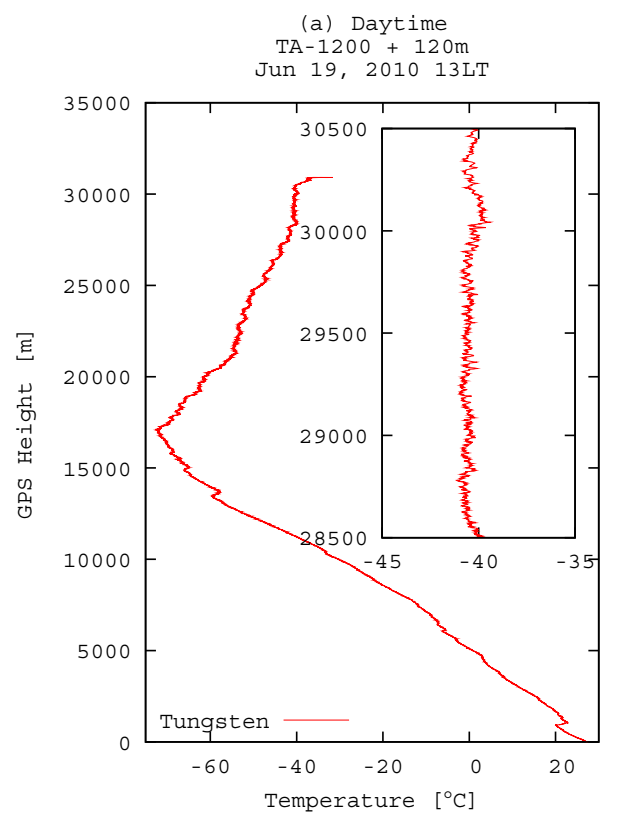

Fig. 11. The same as Fig. 8 (left) but for those taken from the sounding on 19 June 2010 made by using the suspension line of $120 \mathrm{~m}$. In this case, the use of a long suspension line reduces the swing angle to about $10^{\circ}$, while the solar zenith angle is about $42^{\circ}$.

correction necessary to compensate for the insolation is estimated to be less than $0.5 \mathrm{~K}$ in the whole observation range covered by radiosondes. Test flights of the initial model, conducted under varieties of atmospheric and instrumental conditions, detected artificial temperature perturbations that appear as numerous pulses in the stratosphere. They are interpreted as the thermal contamination arising primarily from radiosonde package box with some additional effect from the launching balloon. The former effect has been eliminated by modifying the mount of the sensor, while some filtering procedure will be required to remove the latter, although the use of a long suspension line is sure to reduce the perturbations. Some small fluctuations with the magnitude of less than $0.4 \mathrm{~K}$, that still remain after successful elimination of artificial perturbations, are interpreted as those brought about by the solid angle modulation of the illumination against the sensor body.

The implications from our findings will be:

1. Temperature measurements from conventional radiosondes are subject to artificial perturbations.

2. Smoothing of raw data by simple averaging can never reach true values, as the perturbations are not random but are single-sided either in the positive during the day or in the negative direction during the night.

3. Radiation correction that relies only on the solar zenith angle cannot achieve proper job as the errors are not solely caused by solar heating on the sensor body.
The evidences suggest that historical radiosonde temperature record could be contaminated by thermal perturbations of the sounding system, although their magnitude might not be so large. It is hard to quantify them on each sounding basis as the errors depend on the configuration of flight module as well as the radiosonde make. It should be worth mentioning that appreciable temperature errors could be hidden even in the conventional low-sensitivity sensor data when the observations are made by those sondes attached to special sensors such as ozone sonde equipped in a large styrofoam box.

Our tungsten sonde has an advantage in that the origin of individual perturbations, such as the heat pulse and the solar eclipse due to the overhead balloon, could be separately identified. It may not be recommended for universal use, but is ideal for research purposes such as detecting atmospheric fine structures that may be left unresolved by existing radiosondes. It could also serve as an international reference since it does not rely much on the ambiguous correction procedures. It has participated in the international intercomparison of radiosondes organized by WMO and the results will be published elsewhere. A detailed description on how the contamination appears in the operational sonde data is under preparation.

Acknowledgements. We appreciate helpful discussions and comments by M. Fujiwara, H. Vömel and colleagues of EES, Hokkaido University. We are also grateful to the members of LAPAN, Indonesia, to conduct observations in Biak. Technical support from Meisei Electric Co., Ltd. is deeply appreciated. This work was partly supported by KAKENHI (21244072) and Global Environment Research Fund of the Ministry of the Environment (A-071).

Edited by: M. Wendisch

\section{References}

Abernethy, R. B. and Benedict, R. P.: Measurement uncertainty: A standard methodology, ISA T., 24(1), 75-79, 1985.

Baldwin, M. P. and Dunkerton, T. J.: Stratospheric harbingers of anomalous weather regimes, Science, 294, 581-584, 2001.

Bedka, K. M. and Mecikalski, J. R.: Application of satellite-derived atmospheric motion vectors for estimating mesoscale flows, J. Appl. Meteorol., 44, 1761-1772, 2005.

Brewer, A. W.: Evidence for a world circulation provided by the measurements of helium and water vapour distribution in the stratosphere, Q. J. Roy. Meteor. Soc., 75, 351-363, 1949.

Gaffen, D. J.: Temporal inhomogeneities in radiosonde temperature records, J. Geophys. Res., 99, 3667-3676, 1994.

Hartmann, D. L., Holton, J. R., and Fu, Q.: The heat balance of the tropical tropopause, cirrus, and stratospheric dehydration, Geophys. Res. Lett., 28, 1969-1972, 2001.

Holton, J. R. and Gettelman, A.: Horizontal transport and the dehydration of the stratosphere, Geophys. Res. Lett., 28, 2799-2802, 2001.

Hyson, P.: The tungsten wire temperature sensor, J. Appl. Meteorol., 7, 684-690, 1968. 
Immler, F. J., Dykema, J., Gardiner, T., Whiteman, D. N., Thorne, P. W., and Vömel, H.: Reference Quality Upper-Air Measurements: guidance for developing GRUAN data products, Atmos. Meas. Tech., 3, 1217-1231, doi:10.5194/amt-3-1217-2010, 2010.

Karl, T. R., Hassol, S. J., Miller, C. D., and Murray, W. L.: Temperature Trends in the Lower Atmosphere: Steps for Understanding and Reconciling Differences, A report by the Climate Change Science Program and Subcommittee on Global Change Research, available at: http://www.climatescience.gov/Library/ sap/sap1-1/finalreport/default.htm, last access: 1 August 2010, Washington, DC, 180 pp., 2006.

Kaye, G. W. C. and Laby, T. H.: Online edition, Tables of Physical and Chemical Constants, 2.3.7 Thermal conductivities, available at: http://www.kayelaby.npl.co.uk/, last access: 1 August 2010, 2008.

Luers, J. K. and Eskridge, R. E.: Use of radiosonde temperature data in climate studies, J. Climate, 11, 1002-1019, 1998.

McMillin, L., Uddstrom, M., and Coletti, A.: A procedure for correcting radiosonde reports for radiation errors, J. Atmos. Ocean. Tech., 9, 801-811, 1992.

Mears, C. A. and Wentz, F. J.: The effect of diurnal correction on satellite-derived lower tropospheric temperature, Science, 309, 1548-1551, 2005.

Misra, P. and Enge, P.: Global Positioning System: Signals, Measurements, and Performance, Ganga-Jamuna Press, Lincoln, MA, USA, 2001.

Nash, J., Smout, R., Oakley, T., Pathack, B., and Kurnosenko, S.: WMO Intercomparison of High Quality Radiosonde Systems, Vacoas, Mauritius, 2-25 February 2005, Final Report, available at: http://www.wmo.int/pages/prog/www/IMOP/reports. html, last access: 1 August 2010, 2006.

Newell, R. E. and Gould-Stewart, S.: A stratospheric fountain?, J. Atmos. Sci., 38, 2789-2796, 1981.

Nishida, M., Shimizu, A., Tsuda, T., Rocken, C., and Ware, R. H.: Seasonal and longitudinal variations in the tropical tropopause observed with the GPS occultation technique (GPS/MET), J. Meteorol. Soc. Japn., 78, 691-700, 2000.
Seidel, D. J., Berger, F. H., Diamond, H. J., Dykema, J., Goodrich, D., Immler, F., Murray, W., Peterson, T., Sisterson, D., Sommer, M., Thorne, P., Vömel, H., and Wang, J.: Reference upper-air observations for climate, Rationale, progress, and plans, B. Am. Meteor. Soc., 90, 361-369, 2009.

Sherwood, S. C., Lanzante, J. R., and Meyer, C. L.: Radiosonde daytime biases and late-20th century warming, Science, 309, 1556-1559, 2005.

Solomon, S.: Antarctic ozone: progress towards a quantitative understanding, Nature, 347, 347-354, 1990.

Solomon, S., Qin, D., Manning, M., Marquis, M., Averyt, K., Tignor Jr., M., Miller, H. L., and Chen, Z.: Climate Change 2007: The Physical Science Basis, Contribution of Working Group I to the Fourth Assessment Report of the Intergovernmental Panel on Climate Change, Cambridge University Press, 2007.

Solomon, S., Rosenlof, K. H., Portmann, R. W., Daniel, J. S., Davis, S. M., Sanford, T. J., and Plattner, G.-K.: Contributions of stratospheric water vapor to decadal changes in the rate of global warming, available at: http://www.climatescience.gov/Library/ sap/sap1-1/finalreport/default, last access: 1 August 2010, Science, 327, 1219-1223, 2010.

Thompson, D. W. J. and Solomon, S.: Interpretation of recent Southern Hemisphere climate change, http://www.kayelaby.npl. co.uk/, last access: 1 August 2010, Science, 296, 895-899, 2002.

Thompson, D. W. J. and Wallace, J. M.: Annular modes in the extratropical circulation, Part I: month-to-month variability, J. Climate, 13, 1000-1016, 2000.

Tiefenau, H. K. E. and Gebbeken, A.: Influence of meteorological balloons on temperature measurements with radiosondes: nighttime cooling and daytime heating, J. Atmos. Ocean. Tech., 6, 36-42, 1989.

World Meteorological Organization: Guide to Meteorological Instruments and Methods of Observation, WMO-No. 8, World Meteorological Organization, Geneva, Switzerland, 7 edition, available at: http://www.wmo.int/pages/prog/www/IMOP/ publications/CIMO-Guide/CIMO_Guide-7th_Edition-2008. html, last access: 1 August 2010, 2008.

Yang, Q., Fu, Q., and $\mathrm{Hu}, \mathrm{Y}$. : Radiative impacts of clouds in the tropical tropopause layer, J. Geophys. Res., 115, D00H12, doi:10.1029/2009JD012393, 2010. 